\title{
ОРГАНИЗАЦИОННО-ЭКОНОМИЧЕСКИЙ МЕХАНИЗМ МЕЖФИРМЕННОГО ВЗАИМОДЕЙСТВИЯ *
}

\author{
(C) 2021 Горлачева Е.Н. \\ кандидат экономических наук, доцент кафедры «Промышленная логистика» \\ МГТУ им. Н. Э. Баумана, Россия, Москва
}

(c) 2021 Иванникова Е. М.

кандидат технических наук, доцент кафедры «Процессы и аппараты химической технологии» Московский политехнический университет, Россия, Москва

В статье рассмотрены основные формы межфирменного взаимодействия в условиях дифференциации современной экономики. Разработан организационно-экономический механизм межфирменного взаимодействия, рассмотрены этапы его практической реализации. Разработанный механизм направлен на обеспечение устойчивого развития высокотехнологичных промышленных предприятий за счет комбинации организационных способностей различных экономических агентов.

Ключевые слова: координация, инновации, сетевые структуры, межфирменное взаимодействие, дифференциация экономики.

В настоящее время современная экономика трансформируется в открытое многомерное пространство, которое лишено привычных центов управления [7,9]. Центры координации межфирменного взаимодействия возникают всюду, где образуются распределительные узлы накопления и передачи знаний, что представляет особую актуальность для повышения инновационной активности высокотехнологичных промышленных предприятий [2-4].

Как показывают многочисленные исследования [1,4,5,12], межфирменное взаимодействие, основанное на сетевых объединениях, является перспективным направлением устойчивого развития высокотехнологичных промышленных предприятий. Факторами, стимулирующими высокотехнологичные предприятий к интеграции, выступают недостаток собственных компетенций, технологий, знаний современных методов управления, что в условиях обострения конкурентной борьбы приводит к необходимости закрепления специфических форм интеграции, нежели чем договоренности в рамках стандартных контрактных отношений. В этой случае сетевые формы межфирменного взаимодействия позволяют высокотехнологичным предприятиям найти более или менее эффективные варианты дифференциации и координации труда, обеспечивая накопление различных органи- зационных ресурсов, направленных на усиление конкурентных преимуществ за счет повышения технологического уровня производства, за счет стимулирования инновационной активности, за счет разделения рисков и затрат между партнерами.

Таким образом, современные инновационные процессы, развитие информационнокоммуникационных технологий, динамизм современных товарных рынков требуют и одновременно создают более гибкие и подвижные организационные структуры, отличные от иерархических. Упомянутые выше факторы накапливания знаний, умений, организационных способностей, опыта самостоятельного налаживания производственно-хозяйственных связей и партнерских взаимодействий делают возможными организации с институционально закрепленной меньшей степенью иерархии.

Проблемы организации экономики традиционно изучаются в рамках трех исследовательских направлениях: организации производства (всеобщая организационная наука по А.Богданову [1]) теории фирмы [5] и теории отраслевых рынков [11]. В теоретическом наследии индустриальной экономики последовательно складывались прообразы современного понимания иерархических и сетевых организационных структур отношений экономических агентов.

* Исследование выполнено в рамках гранта РФФИ №19-010-00348\19 
Попытки объяснить процессы, совершающиеся в рамках фирмы, обосновать границы фирмы в рыночном пространстве, увидеть природу и формы рыночных взаимодействий и рыночной координации последовательно предпринимались в рамках теории фирмы (Р.Коуза) [5], институционализма (О.Уильямсона) [12], теории отраслевых рынков (Ж. Тироль) [11]. Если посмотреть, какие отношения в конечном итоге лежат в основе современных бизнес-процессов, обеспечивающих цепочки создания добавленной стоимости в современной экономике, то можно увидеть разнообразные формы межфирменного взаимодействия - стратегические альянсы, франчайзинговые соглашения, кластеры и различные объединения.

Необходимость экономического анализа истоков саморазвития организации привела к формированию ресурсного подхода (Э. Пенроуз) [13], в рамках которого считается, что поток стоимости создается за счет наличия коллективных ресурсов, а сама фирма рассматривается как сеть административных отношений, координирующих использование фонда ресурсов в различных целях. В ресурсном подходе также отражена еще одна ключевая особенность межфирменных взаимодействий: способность создавать необходимые кооперационные связи в такой форме, в какой рынок это сделать не может.

Наличие динамических транзакционных издержек (издержки убеждения, ведения переговоров, координации действий) требует от предприятия оперативного использования новых знаний и умений, которыми она не располагает, но может либо получить у внешних организаций, либо вырастить самостоятельно, что неизбежно требует времени и затрат. Поэтому целесообразнее на возмездных условиях кооперироваться с теми, кто располагает данным ресурсом.

С точки зрения организации сетевая структура может пониматься в широком и узком смысле [9]. В широком смысле сеть - это система из элементов (узлов), соединенных линиями (связями, ребрами). В более узком - сетевая структура - децентрализованная структура из элементов, которые кооперируются между собой в процессе какой-либо деятельности. В этом понимании сетевая структура противопоставляется иерархическим структурам, где имеется центральное управляющее звено. В то же время допущение кооперации составляющих элемен- тов отграничивает сетевую структуру от (квази) рыночной структуры, в которой элементы не кооперируют, а конкурируют друг с другом. В отсутствие центрального управляющего звена перед сетевыми структурами встает проблема координации ее звеньев. Координирующую роль выполняет матрица, которая может иметь как материальное воплощение, но чаще нематериальное (объединяющие нормы, ценности, идеи, конвенции). Матрица объединяет цели и представления о путях их достижения, общие морально-этические нормы, правила делового общения, общие намерения, устремления и миссии.

Рассмотрим формы межфирменного взаимодействия, представленные на рис. 1 [4]. Задача высокотехнологичного предприятия состоит в том, чтобы определить организационную структуру, позволяющую обеспечить эффективный способ координации посредством использования рынка, иерархии или гибридных форм межфирменного взаимодействия.

В таблице 1 представлены характерные черты, присущие основным технологиям координации: рынка, иерархической организации, гибридных форм взаимодействия.

Процесс межфирменного взаимодействия обусловливает необходимость разработки специфического механизма, в котором будут отражены уровни взаимодействия; субъекты взаимодействия; формы, методы и инструменты взаимодействия, а также результаты взаимодействия $[6,8,10]$. В качестве уровней взаимодействия можно выделить: макро- (глобальный уровень); мезо -(национальный уровень); микро- (уровень отдельных экономических агентов). Субъектами взаимодействия являются экономические агенты различных организационно-правовых форм и собственности. В качестве форм взаимодействия можно выделить стратегические партнерства, контрактное производство, субконтрактацию. В качестве методов и инструментов управления: проектное управление, создание совместных научно-исследовательских лабораторий; трансфер технологий; совместное производство. В качестве результатов межфирменного взаимодействия является: увеличение доли на приоритетных рынках, экономия затрат на научно-исследовательскую деятельность, увеличение инвестиционных возможностей, интеграция в глобальные производственные цепочки. 


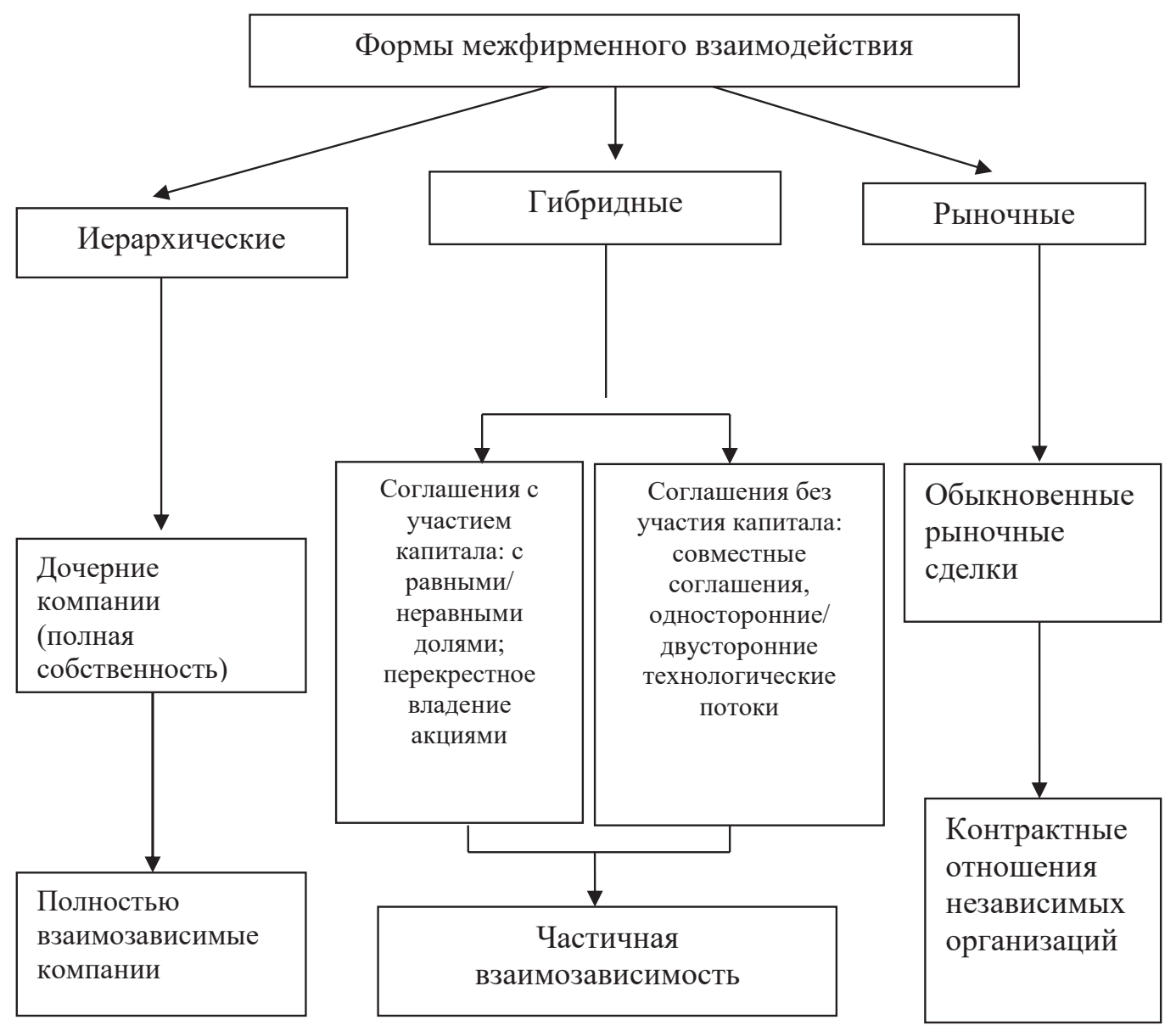

Рис. 1. Формы межфирменного взаимодействия

Таблица 1. Особенности координации

\begin{tabular}{|l|l|l|l|}
\hline Технологии координации & Рынок & $\begin{array}{l}\text { Иерархическая } \\
\text { организация }\end{array}$ & $\begin{array}{l}\text { Гибридные формы } \\
\text { взаимодействия }\end{array}$ \\
\hline Нормативная база & $\begin{array}{l}\text { Право собственности, } \\
\text { юридически скрепленные } \\
\text { контракты }\end{array}$ & $\begin{array}{l}\text { Отношенение взаимных найма } \\
\text { обязательств }\end{array}$ \\
\hline Средства коммуникации & Цены & $\begin{array}{l}\text { Административные } \\
\text { процедуры }\end{array}$ & Установившаяся практика \\
\hline $\begin{array}{l}\text { Методы разрешения } \\
\text { конфликтов }\end{array}$ & Обращение в суд & Административные & $\begin{array}{l}\text { Переговоры (преимуще- } \\
\text { ственно неформальные) }\end{array}$ \\
\hline Степень гибкости & Высокая & Низкая & Средняя \\
\hline $\begin{array}{l}\text { Уровень взаимных } \\
\text { обязательств }\end{array}$ & Незначительный & Средний либо высокий & Средний \\
\hline
\end{tabular}


Схематично механизм межфирменного взаимодействия представлен на рис. 2.

Практическая реализация механизма межфирменного взаимодействия включает три основных этапа:

Подготовительный. На данном этапе определяются целесообразность, цели и задачи межфирменного взаимодействия. Для выполнения работ в рамках межфирменного взаимодействия следует сформировать рабочую группу, в которую войдут специалисты из финансовой, маркетинговой службы, планово-экономического отдела, информационно-аналитических подразделений. Рабочая группа должны осуществлять сбор и обработку информации стратегии развития высокотехнологичного предприятия, необходимости межфирменного взаимодействия, распределении функционала между структурными подразделениями, обоснования научнометодологического аппарата, обоснования системы количественных показателей, отражающих результативность межфирменного взаимодействия.

Процессуальный. На данном этапе необходимо реализовать запланированные мероприятия. После установления формы реализации межфирменного взаимодействия, составляется смета затрат на осуществление проекта по межфирменному взаимодействию, рассчитывается стоимость. Проводится информирование персо- нала и поясняется суть и предпосылки внедрения межфирменного взаимодействия, особенности работы с новыми формами отчетности. Реализация механизма межфирменного взаимодействия должна осуществляться на основе четко закрепленных и регламентированных мероприятий по исполнению функций и задач управления. Такая регламентация может осуществляться в процессе создания внутренних нормативных документов.

Заключительный. Проводится контроль достижения запланированных результатов. И выявляются причины полученных отрицательных результатов. Рабочая группа проводит мониторинг эффективности межфирменного взаимодействия и составляет отчет о результатах.

Ведущим исполнителем является отдел стратегического развития, в задачи которого входят решение следующих управленческих вопросов: сбор и анализ о целесообразности межфирменного взаимодействия на основе анализа рынка, современных тенденций, технологического развития, обеспечение структурных подразделений специализированными аналитическими материалами, отслеживание сведений о выставках, конференциях, семинарах, установление взаимоотношений с ведущими научноисследовательскими центрами, координация информационно-аналитической работы.

Практическая реализация механизма меж-

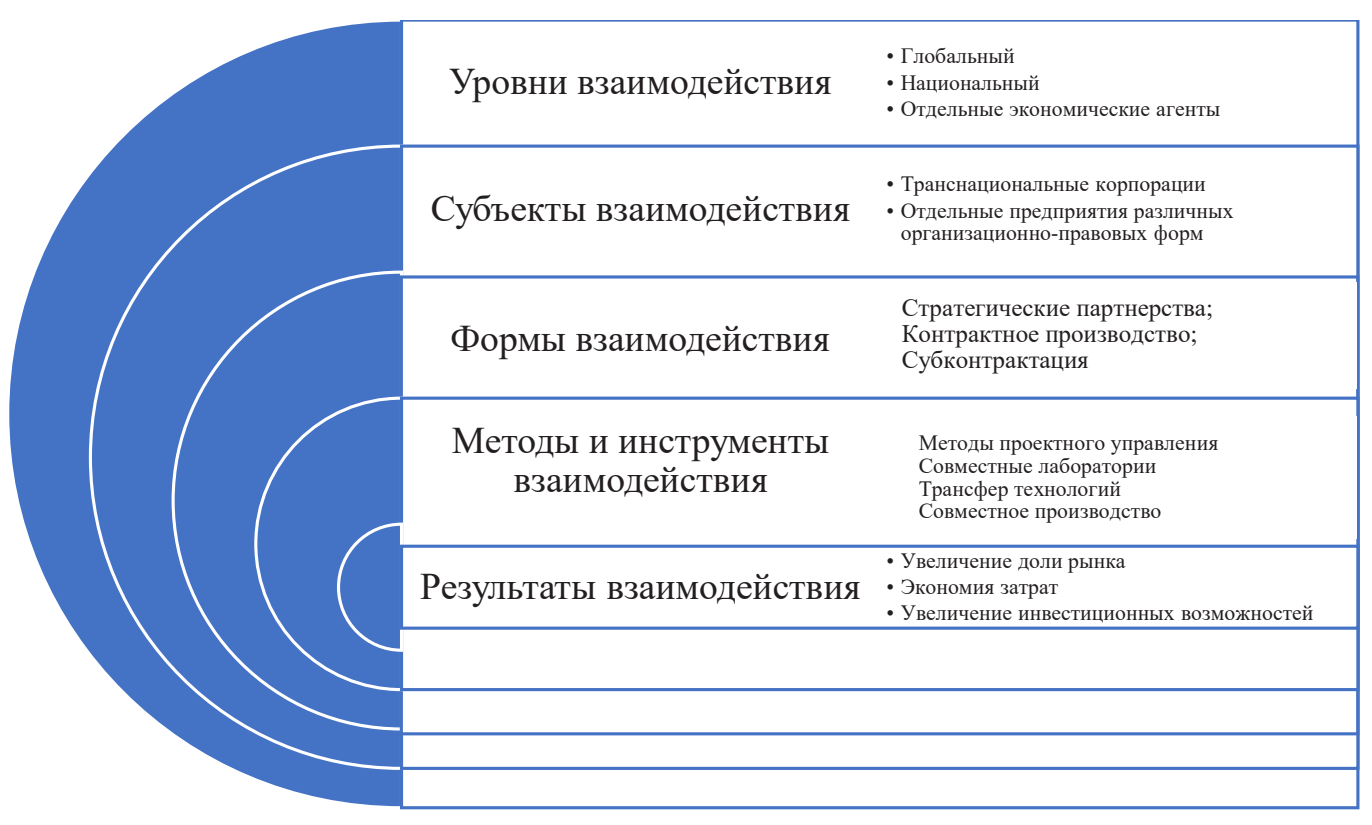

Puc. 2. Механизм межфирменного взаимодействия 
фирменного взаимодействия позволит достичь следующих результатов:

- повысить эффективность устойчивого развития высокотехнологичного предприятия за счет межфирменного взаимодействия;

- обосновать релевантность применяемых мероприятий для достижения поставленных стратегических целей;

- снизить риски, связанные с разработкой и внедрением инновационной наукоемкой продукции.

Таким образом, межфирменное взаимодействие наиболее продуктивно при высокой неопределенности внешней среды и раздробленности знаний, обеспечивая участников достаточно гибкими средствами к их накоплению; при высокой «абсорбционной» способности предприятия к обучению и адаптации полученных знаний. Однако гибридные формы взаимодействия предъявляют к партнерам более высокие требования в вопросах лидерства, доверия и вовлеченности. Даже если партнеры обладают взаимодополняющими способностями, они не всегда готовы поделиться с ними, особенно если компании являются конкурентами. Феномен «изобретено не здесь» нередко обусловливает недооценку способностей, которые привносит в кооперацию другая сторона.

Однако, изменяющиеся внешние условия - возрастающая сложность и высокие темпы инновационных изменений - заставляют предприятия придерживаться более открытых позиций. К тому же распространение определенных типов ноу-хау тоже может быть прибыльным. Если собственная технология предприятия является доминирующей в отрасли, предприятие приобретает весомые конкурентные преимущества. Однако доминирующая позиция в новейших технологиях предполагает необходимость постоянного развития потребительских свойств высокотехнологичной продукции. Именно поэтому на рынке высоких технологий выпуск новой продукции часто происходит до насыщения рыночной потребности и диктуется необходимостью укрепления или сохранения лидирующей позиции. Поскольку источники технологических идей часто оказываются вне корпоративной структуры, увеличивается ценность межфирменного взаимодействия, способность удержать в поле своего контроля по возможности более широкое количество технологических и рыночных инициатив.

\section{Библиографический список}

1. Богданов А. А. Тектология: всеообщая организационная наука. В 2= кн.: Кн.1. М.: Экономика. 1989. 304 с.

2. Горлачева E.H. Оценка результативности межфирменного взаимодействия // Наукоемкие технологии. 2011.№ 10. C.41-50.

3. Горлачева Е.Н., Гудков А.Г., Омельченко И.Н. Стратегические технологические альянсы // Нелинейный мир. 211. № 4. С.43-54.

4. Горлачева Е.Н., Гудков А.Г., Омельченко И. Н. Технологии межфирменного взаимодействия. М.: Сайнс-Пресс. 2015. 184 c.

5. Коуз Р. Фирма, рынок и право: пер. с англ. М.: Дело, 1993. 192 с.

6. Курганов Ю.А. Международная кооперация - катализатор диверсификации и инноваций // Российский внешнеэкономический вестник. 2013. № 10. С.9-16.

7. Мезоэкономика: элементы новой парадигмы. / под ред. В.И. Маевского, С. Г.Кирдиной-Чэндлер. М.: ИЭ РАН. 2020. 392 c.

8. Никулина О.В., Кузнецов А. А. Международная кооперация как механизм взаимодействия промышленных предприятий в сфере инноваций // Национальные интересы: приоритеты и безопасность. 2016. № 4. С.88102.

9. Олескин А.В., Курдюмов В. С. Сетевые структуры: опции в мире живого и человеческом социуме // Экономические стратегии. 2016. № 7.С.74-85.

10. Пискулов Ю.В., Посываев Ю. Ю., Савинов Ю.А. Концептуальные черты современной межфирменной производственной кооперации // Российский внешнеэкономический вестник. 2014. № 11. С.42-59.

11. Тироль Ж. Рынки и рыночная власть: теория организации промышленности: в 2х т.: пер. с англ. / под ред. В. М. Гальперина и Н.А. Зенкевича. СПб.: Экономическая школа. 2000. Т.1. 328 с.

12. Уильямсон О.И. Экономические институты капитализма. Фирмы, рынки, «отношенческая» контрактация / пер. с англ. СПб.: 1996. 702 с.

13. Пенроуз Э.Penrose E. T. 1996 Growth of the firm and networking. International Encyclopaedia of Business and Management. Routledge: London; 1716-1724. 